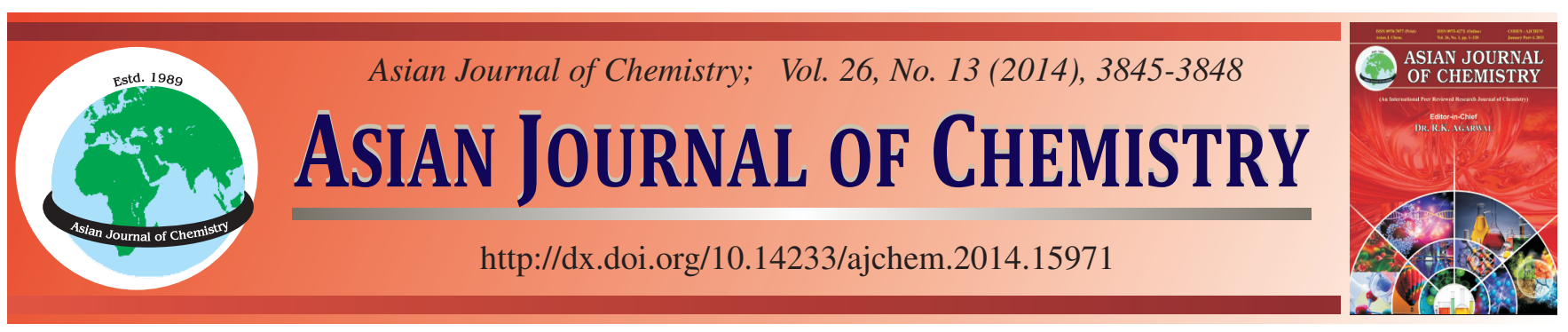

\title{
Novel Silica-Based Hybrid Adsorbents: Copper(II) Adsorption Isotherms and Thermodynamics
}

\author{
Keyan Hu, Junsheng Liu*, Xinghua Chen, Min Xu and Kechun Wang
}

Key Laboratory of Membrane Materials \& Processes, Department of Chemical and Materials Engineering, Hefei University, 99 Jinxiu Road, Hefei Economic and Technological Development Zone, Hefei 230601, P.R. China

*Corresponding author: Fax: +86 551 62158437; Tel: +86 551 62158439; E-mail: jsliu@hfuu.edu.cn

\begin{abstract}
In this study, copper(II) adsorption isotherms and thermodynamic data have been investigated using a hybrid membrane as an adsorbent. It is found that copper(II) adsorption on sample D followed the Freundlich isotherm model. Moreover, it is found that the adsorption capacity of copper(II) on sample D increases with an increase in solution temperature and the $\Delta \mathrm{G}$ values are changed from positive to negative as the temperature increased, suggesting that copper(II) adsorption is an endothermic and spontaneous in nature as the solution temperature was elevated to higher level. In addition, based on intraparticle diffusion, it is confirmed that copper(II) adsorption is not governed by intraparticle diffusion and diffusion-controlled adsorption mechanism might be the major control process. This finding is meaningful in the removal of copper(II) from aqueous solution using hybrid membrane as an adsorbent.
\end{abstract}

Keywords: Hybrid membrane, Adsorption, Isotherms, Thermodynamics, Copper(II) removal.

\section{INTRODUCTION}

Water pollution caused by toxic heavy-metal ions, such as $\mathrm{Cu}^{2+}, \mathrm{Pb}^{2+}$, etc. has become a major environmental issue ${ }^{1-3}$. As a typical toxic heavy-metal, copper(II) pollution has captured much attention. To eliminate or reduce copper(II) pollution, various techniques have been developed ${ }^{1,2,4,5}$. Among which, silica-based hybrid membranes with functionalized ionic groups indicates excellent adsorption performances for heavymetal ions when they are used as hybrid adsorbents ${ }^{5,6}$. However, the applications of these hybrid membranes are restricted within a small field. Especially, the relevant engineering data for their applications in industrial processes are deficient. Therefore, these previous researches are insufficient and further study is essential.

To extend the application aspects of hybrid membrane as adsorbents, a series of novel hybrid membranes using as adsorbents are recently developed and some associated engineering data for their applications in industry are calculated ${ }^{7-9}$. Our continuing interest in these hybrid adsorbents drives us to do further work. Consequently, based on the previous investigation $^{9}$, herein, the adsorption isotherm and thermodynamics of copper(II) ions on silica-based hybrid membranes will be calculated. Its adsorption for copper(II) removal in aqueous solution will be evaluated as a model toxic heavy-metal.

\section{EXPERIMENTAL}

The preparation of hybrid membrane sample used in this case was described in a previous article ${ }^{9}$. In the previous study, it is found that the adsorption capacity of copper(II) on sample A-D increased with an increase in TMSPEDA content. Especially, when the volume ratio of GPTMS and TMSPEDA was 1:10 for sample $\mathrm{D}$, the adsorption capacity of copper(II) in $0.01 \mathrm{~mol} \mathrm{dm}^{-3}$ aqueous $\mathrm{Cu}\left(\mathrm{NO}_{3}\right)_{2}$ solution for $24 \mathrm{~h}$ can arrive at the highest value among the investigated samples A-D. To continue the previous study and the related chemical engineering data, the adsorption isotherm and thermodynamic data of copper(II) ions on sample D will be examined in this job.

Adsorption experiment: To insight into the adsorption properties of these hybrid membranes for copper(II) ions in aqueous solution, adsorption experiment was conducted. The adsorption capacity $\left(\mathrm{q}_{\mathrm{Cu}^{2+}}\right)$ of copper(II) ions can be determined using eq. 1:

$$
\mathrm{q}_{\mathrm{Cu}^{2+}}=\frac{\left(\mathrm{C}_{0}-\mathrm{C}_{\mathrm{R}}\right) \mathrm{V}}{\mathrm{W}}
$$

where $\mathrm{V}(\mathrm{mL})$ is the volume of aqueous $\mathrm{Cu}\left(\mathrm{NO}_{3}\right)_{2}$ solution, $\mathrm{C}_{0}\left(\mathrm{~mol} \mathrm{dm}^{-3}\right)$ and $\mathrm{C}_{\mathrm{R}}\left(\mathrm{mol} \mathrm{dm}^{-3}\right)$ are the concentration of initial and remaining $\mathrm{Cu}\left(\mathrm{NO}_{3}\right)_{2}$, respectively; $\mathrm{W}(\mathrm{g})$ is the weight of hybrid membrane. 


\section{RESULTS AND DISCUSSION}

It is well known that both Langmuir and Freundlich isotherm equations are two typical theoretical models to evaluate the adsorption properties of metal ions on the interface of a solid material. Generally speaking, Langmuir isotherm equation can be expressed as eqn. $2^{10,11}$, which is mainly based on the monolayer adsorption on the active reaction sites of the adsorbent.

$$
\frac{\mathrm{C}_{\mathrm{e}}}{\mathrm{q}_{\mathrm{e}}}=\frac{\mathrm{C}_{\mathrm{e}}}{\mathrm{Q}_{\mathrm{m}}}+\frac{1}{\mathrm{Q}_{\mathrm{m}} \mathrm{b}}
$$

where $\mathrm{q}_{\mathrm{e}}\left(\mathrm{mmol} \mathrm{g}^{-1}\right)$ and $\mathrm{Ce}\left(\mathrm{mol} \mathrm{dm} \mathrm{dm}^{-3}\right)$ are the equilibrium concentrations of metal ion in the adsorbed and liquid phases, respectively. $\mathrm{Q}_{\mathrm{m}}\left(\mathrm{mmol} \mathrm{g}^{-1}\right)$ and $\mathrm{b}\left(\mathrm{dm}^{3} \mathrm{~mol}^{-1}\right)$ are the Langmuir constants, which can be calculated from the intercept and slope of the linear plot based on $\mathrm{C}_{\mathrm{e}} / \mathrm{q}_{\mathrm{e}}$ versus $\mathrm{C}_{\mathrm{e}}$.

Differentiating from the Langmuir isotherm model, Freundlich isotherm equation can be expressed as eqns. (3a) and $(3 b)^{10,11}$. Usually, it is considered as the adsorption occurred on a heterogeneous surface with uniform energy.

$$
\begin{gathered}
\mathrm{q}_{\mathrm{e}}=\mathrm{k}_{\mathrm{F}} \mathrm{C}_{\mathrm{e}}^{\frac{1}{\mathrm{n}}} \\
\log \left(\mathrm{q}_{\mathrm{e}}\right)=\log \mathrm{k}_{\mathrm{F}}+\frac{1}{\mathrm{n}} \log \left(\mathrm{C}_{\mathrm{e}}\right)
\end{gathered}
$$

where $\mathrm{q}_{\mathrm{e}}\left(\mathrm{mmol} \mathrm{g}^{-1}\right)$ and $\mathrm{C}_{\mathrm{e}}\left(\mathrm{mol} \mathrm{\textrm {dm } ^ { - 3 }}\right)$ are the equilibrium concentrations of metal ion in the adsorbed and liquid phases,

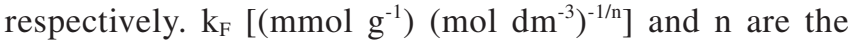
Freundlich constants, which can be calculated from the slope and intercept of the linear plot according to $\log \left(\mathrm{q}_{\mathrm{e}}\right)$ vs. $\log$ $\left(\mathrm{C}_{\mathrm{e}}\right)$.

The relationship of adsorption capacity of copper(II) ions with initial solution concentration (i.e., adsorption isotherm of copper(II) ions) is illustrated in Fig. 1. It can be noted in Fig. 1 that the adsorption capacity of copper(II) ions increases when the concentration of initial solution increases.

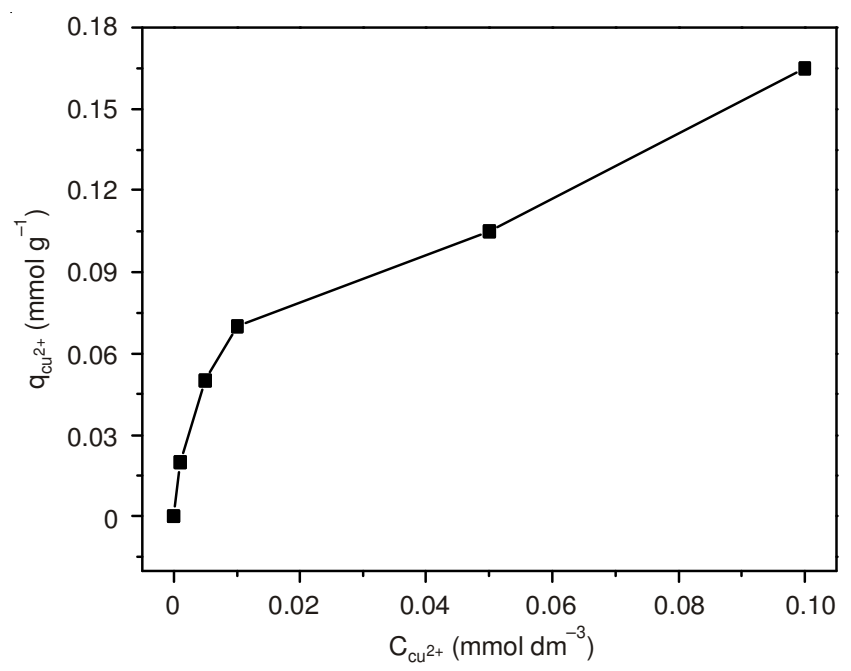

Fig. 1. Copper(II) adsorption capacity versus initial concentration; the sample was immersed in different concentration aqueous $\mathrm{Cu}\left(\mathrm{NO}_{3}\right)_{2}$ solutions for $9 \mathrm{~h}$, respectively
Based on the relationship of copper(II) adsorption capacity with initial solution concentration, Langmuir and Freundlich adsorption isotherms can be calculated. Fig. 2 (a) and (b) presents the Langmuir and Freundlich adsorption isotherm of copper(II) ions. According to these isotherm curves, the Langmuir and Freundlich isotherm parameters are calculated and listed in Table-1. From Table-1, it can be found that that the experimental data fitted well with Freundlich isotherm equation $\left(R^{2}>0.98\right)$. In contrast, these data fitted worse with Langmuir isotherm equation $\left(\mathrm{R}^{2}<0.94\right)$. This finding evidences that copper(II) adsorption on the prepared hybrid membrane is heterogeneous surface adsorption rather than Langmuir monolayer one. Such result will be very meaningful in the removal of copper(II) from aqueous solution using hybrid adsorbents.
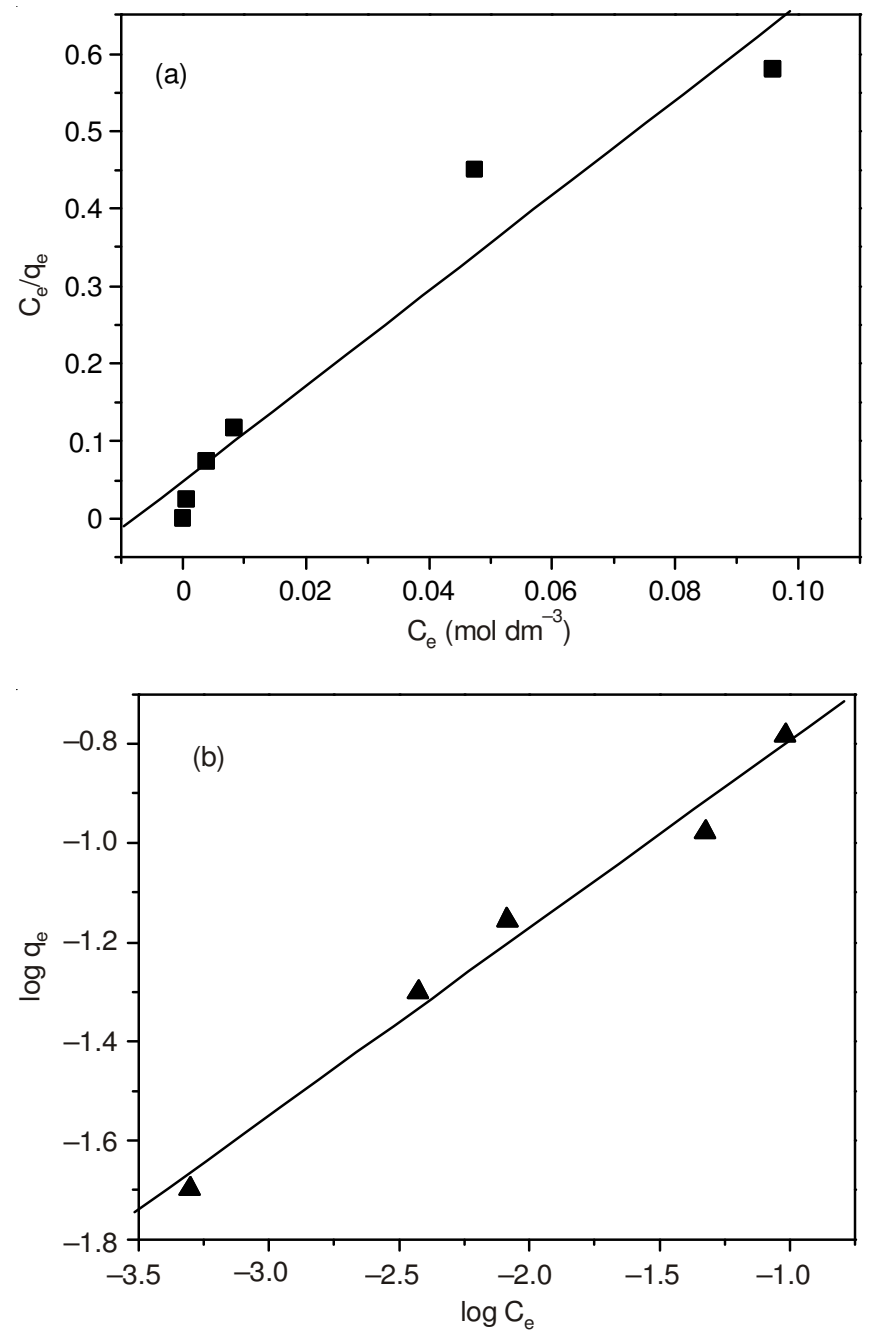

Fig. 2. Plot of adsorption isotherm for copper(II) adsorption, (a) Langmuir model, (b) Freundlich model

TABLE-1

LANGMUIR AND FREUNDLICH ISOTHERM PARAMETERS FOR COPPER(II) ADSORPTION

\begin{tabular}{cccc|ccc}
\hline \multirow{2}{*}{ Sample } & \multicolumn{3}{c|}{ Langmuir } & \multicolumn{3}{c}{ Freundlich } \\
\cline { 2 - 7 } & $\mathrm{Q}_{\mathrm{m}}$ & $\mathrm{b}$ & $\mathrm{R}^{2}$ & $\mathrm{k}_{\mathrm{F}}$ & $\mathrm{n}$ & $\mathrm{R}^{2}$ \\
\hline $\mathrm{D}$ & 0.162 & 125.371 & 0.936 & 0.386 & 2.636 & 0.981 \\
\hline
\end{tabular}


Thermodynamic study: Thermodynamic parameter calculation is vital importance for the removal of heavy-metal ions via adsorption technique. The adsorption experiments at different temperatures for copper(II) removal are thus performed and illustrated in Fig. 3.

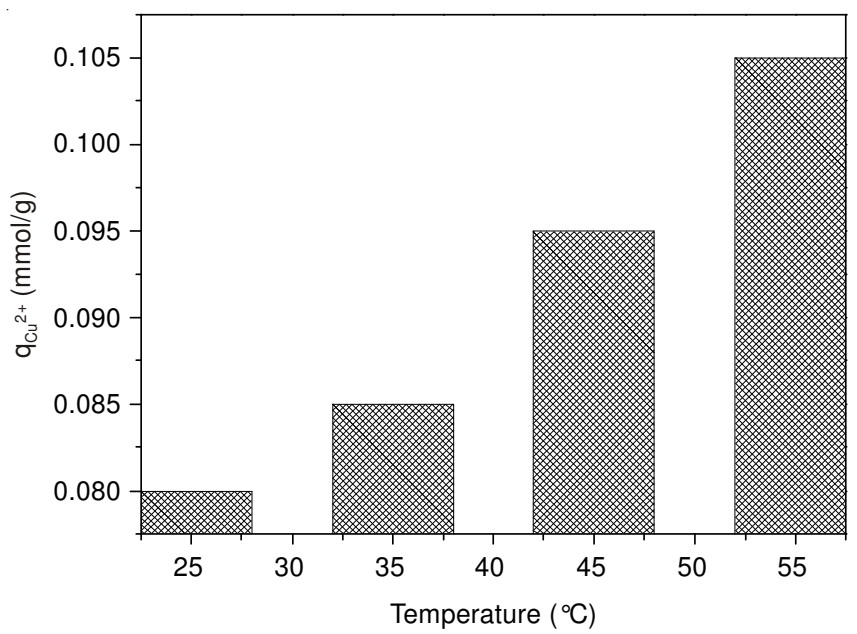

Fig. 3. Copper(II) adsorption capacity versus solution temperature, the concentration of aqueous $\mathrm{Cu}\left(\mathrm{NO}_{3}\right)_{2}$ solution was $0.01 \mathrm{~mol} \mathrm{dm}{ }^{-3}$

As shown in Fig. 3, it can be seen that the adsorption capacity of copper(II) increases with an increase in solution temperature [the linear regression coefficient $\left(\mathrm{R}^{2}\right)$ values are in the range of 0.91-0.96]. This result indicates that adsorption of copper(II) ions is endothermic in nature ${ }^{10}$, which can be confirmed by some thermodynamic parameters such as free energy $(\Delta \mathrm{G})$ and enthalpy $(\Delta \mathrm{H})$, etc.

Furthermore, thermodynamic parameters, free energy $(\Delta \mathrm{G})$, enthalpy $(\Delta \mathrm{H})$ and entropy $(\Delta \mathrm{S})$, can be calculated from eqns. (4) and (5) ${ }^{10}$

$$
\begin{aligned}
& \Delta \mathrm{G}=-\mathrm{RT} \ln \left(\mathrm{K}_{\mathrm{c}}\right) \\
& \ln \left(\mathrm{K}_{\mathrm{c}}\right)=\frac{\Delta \mathrm{S}}{\mathrm{R}}-\frac{\Delta \mathrm{H}}{\mathrm{RT}}
\end{aligned}
$$

in which, $\mathrm{K}_{\mathrm{c}}$ is the equilibrium partition coefficient and can be calculated from eq. $(6)^{10}$ :

$$
\mathrm{K}_{\mathrm{c}}=\frac{\mathrm{C}_{\mathrm{s}}}{\mathrm{C}_{\mathrm{e}}}
$$

where $\mathrm{R}$ is the gas constant $(8.314 \mathrm{~J} / \mathrm{mol} \mathrm{K}), \mathrm{C}_{\mathrm{s}}$ and $\mathrm{C}_{\mathrm{e}}(\mathrm{mol}$ $\left.\mathrm{dm}^{-3}\right)$ are the equilibrium concentrations of metal ions in the adsorbent and solution, respectively and $\mathrm{T}$ is the solution temperature $(\mathrm{K}) . \Delta \mathrm{H}$ and $\Delta \mathrm{S}$ can thus be calculated from the slope and intercept of the linear plot according to $\ln \left(\mathrm{K}_{\mathrm{c}}\right)$ versus 1/T (cf. Fig. 4). The calculated results are presented in Table- 2.

TABLE-2

THERMODYNAMIC DATA FOR COPPER(II) ADSORPTION

\begin{tabular}{cccccc}
\hline Sample & $\begin{array}{c}\text { Temp. } \\
(\mathrm{K})\end{array}$ & $\begin{array}{c}\Delta \mathrm{G} \\
(\mathrm{kJ} / \mathrm{mol})\end{array}$ & $\begin{array}{c}\Delta \mathrm{S} \\
(\mathrm{J} / \mathrm{mol} \mathrm{K})\end{array}$ & $\begin{array}{c}\Delta \mathrm{H} \\
(\mathrm{kJ} / \mathrm{mol})\end{array}$ & $\mathrm{R}^{2}$ \\
\hline $\mathrm{D}$ & 298.15 & 1.005 & 43.043 & 13.922 & 0.973 \\
& 308.15 & 0.774 & & & \\
& 318.15 & 0.265 & & & \\
& 328.15 & -0.273 & & & \\
\hline
\end{tabular}

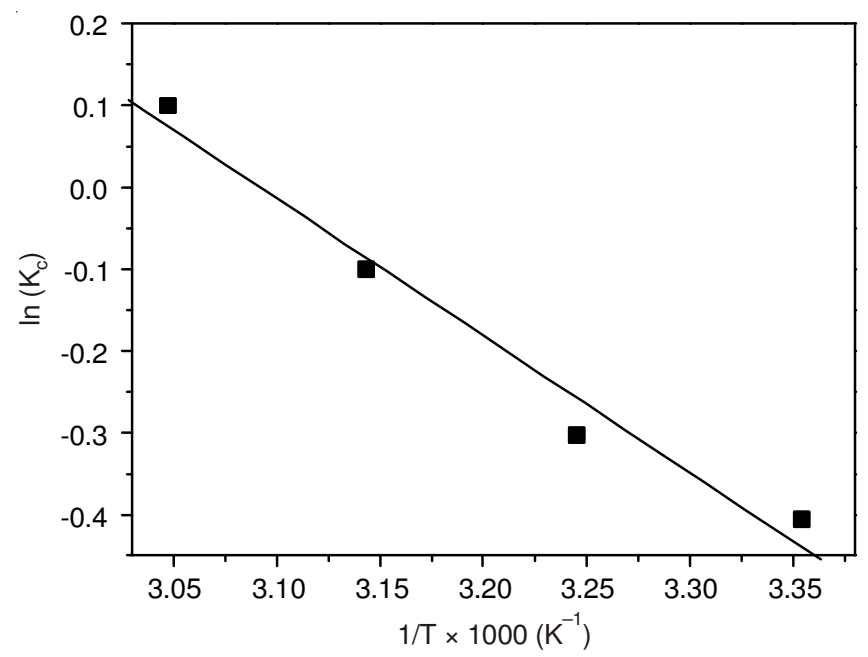

Fig. 4. van't Hoff plot of copper(II) adsorption, the concentration of aqueous $\mathrm{Cu}\left(\mathrm{NO}_{3}\right)_{2}$ solution was $0.01 \mathrm{~mol} \mathrm{dm}^{-3}$ at $25,35,45$ and $55^{\circ} \mathrm{C}$ for 24 $\mathrm{h}$, respectively

As shown in Table-2, the $\Delta \mathrm{G}$ values are changed from positive to negative with the elevated solution temperature. Meanwhile, the $\Delta \mathrm{H}$ values are all positive in the tested temperature range. These observations imply that copper(II) adsorption on the prepared hybrid membrane is spontaneous and endothermic process when the solution temperature is elevated to higher level. Moreover, it can be seen that the $\Delta S$ values are all positive, demonstrating that the randomness increased during copper(II) adsorption on sample D. These findings evidence that temperature has a larger impact on copper(II) adsorption on the investigated hybrid membrane.

Intraparticle diffusion mechanism: It is reported that when metal ions are adsorbed by an adsorbent, the metal ions transport from the solution through the interface between the solution and the adsorbent into the pores of the particles. Such transport property of metal ions can be modeled via intraparticle diffusion ${ }^{11}$. To gain the interface transport property of copper(II) ions from the interior of the prepared sample D, intraparticle diffusion model was determined. The intraparticle diffusion on the adsorption rate of copper(II) ions can be calculated according to the dependency of adsorption capacity $\mathrm{q}_{\mathrm{t}}$ on contact time $\mathrm{t}$, which can be expressed as eq. (4) ${ }^{12}$.

$$
\mathrm{q}_{\mathrm{t}}=\mathrm{x}_{\mathrm{i}}+\mathrm{k}_{\mathrm{p}} \mathrm{t}^{0.5}
$$

where $\mathrm{q}_{\mathrm{t}}\left(\mathrm{mmol} \mathrm{g}^{-1}\right)$ is the adsorbed amount at time $\mathrm{t}(\mathrm{h}), \mathrm{k}_{\mathrm{p}}$ $\left(\mathrm{mmol} \mathrm{g}{ }^{-1} \mathrm{~h}^{-1 / 2}\right)$ is the intraparticle diffusion rate constant and $\mathrm{X}_{\mathrm{i}}\left(\mathrm{mmol} \mathrm{g}^{-1}\right)$ is the intercept of straight line, which is related to the boundary layer thickness.

Presently, it is well accepted that if the plot of $\mathrm{q}_{\mathrm{t}} v s . \mathrm{t}^{0.5}$ gives a straight line, the adsorption process is solely controlled by intraparticle diffusion. In contrast, if the linear fitting exhibit multi-linear curves, two or more steps will influence the adsorption process ${ }^{11,12}$.

Fig. 5 gives the intraparticle diffusion curve of copper(II) adsorption on sample D. From Fig. 5, it can be noted that the graph doesn't exhibit the straight line and the linear regression coefficient $\left(\mathrm{R}^{2}\right)$ fitted worse for copper(II) adsorption as the tested data are linearly fitted. This result copper(II) adsorption on the prepared hybrid membrane is not governed by intra- 


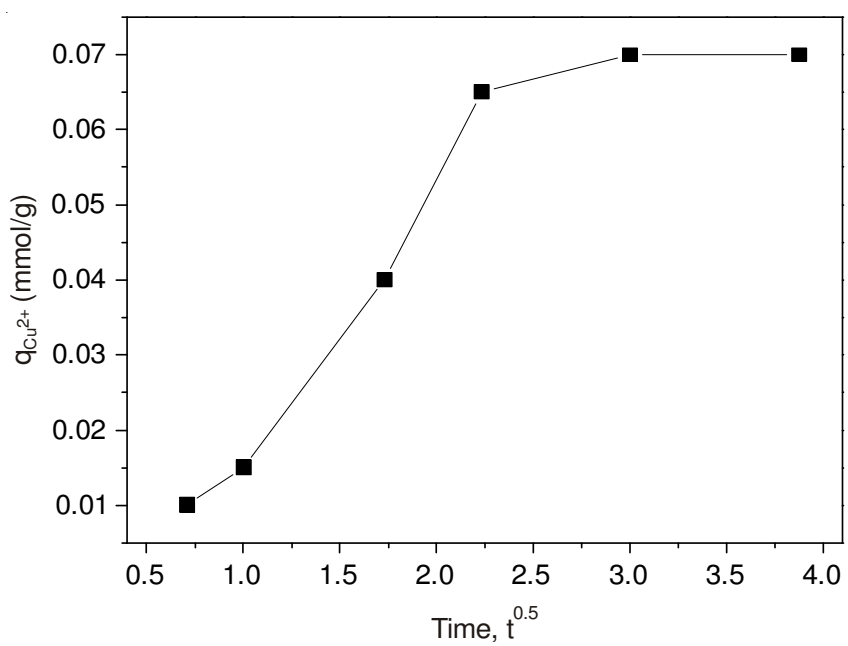

Fig. 5. Intraparticle diffusion curve of copper(II) adsorption on sample D

particle diffusion and diffusion-controlled adsorption mechanism might be the major control process.

Desorption experiment: Currently, for the removal of heavy metal ions from aqueous solution, the significance consists in both desorption and reuse of metal ion in industrial processes rather than the simple adsorption and disposal ${ }^{6,13}$. To regenerate and recycle the adsorbent spent, desorption experiment was performed using $0.1 \mathrm{~mol} \mathrm{dm}^{-3} \mathrm{HCl}, \mathrm{H}_{2} \mathrm{SO}_{4}$ and $\mathrm{HNO}_{3}$ as typical desorbents, respectively. The obtained data are listed in Table-3. Clearly, for copper(II) desorption, the desorption efficiency (\%) can be elevated to $100 \%$ demonstrating an effective regeneration cycle.

\begin{tabular}{lcc}
\multicolumn{3}{c}{ TABLE-3 } \\
\multicolumn{3}{c}{$\begin{array}{c}\text { DESORPTION EFFICIENCY OF SAMPLE D FOR } \\
\text { COPPER(II) IN VARIOUS DESORBENTS }\end{array}$} \\
\hline \multicolumn{1}{c}{ Desorbent } & Desorption time (h) & Efficiency (\%) \\
\hline $\mathrm{HCl}$ & 9 & 99.3 \\
$\mathrm{H}_{2} \mathrm{SO}_{4}$ & 9 & 100 \\
$\mathrm{HNO}_{3}$ & 9 & 100 \\
\hline
\end{tabular}

Based on the above obtained desorption data, it can be concluded that this type of hybrid membrane is a promising adsorbent for removal of copper(II) from copper(II)-bearing water in industry.

\section{Conclusion}

Copper (II) adsorption isotherms and thermodynamic data are examined. It is demonstrates that copper(II) adsorption on sample D followed the Freundlich isotherm model. The calculation of thermodynamic parameters indicates solution temperature has an important impact on copper(II) adsorption and such adsorption is an endothermic in nature. In addition, the measurement of intraparticle diffusion suggests that copper(II) adsorption is not governed by intraparticle diffusion and diffusion-controlled adsorption mechanism might be the major control step.

\section{ACKNOWLEDGEMENTS}

This project was financially supported by the National Natural Science Foundation of China (No. 21076055), the Significant Foundation of Educational Committee of Anhui Province (No. ZD2008002-1), the 2th National-level College Students' Innovative Entrepreneurial Training Plan Program (No. 201211059010).

\section{REFERENCES}

1. J. Li, S.W. Zhang, C.L. Chen, G.X. Zhao, X. Yang, J.X. Li and X.K. Wang, ACS Appl. Mater. Interfaces, 4, 4991 (2012).

2. S.A. Ali, O.C.S. Al Hamouz and N.M. Hassan, J. Hazard. Mater., 248, 47 (2013).

3. M. Karatas, J. Hazard. Mater., 199, 383 (2012).

4. J.-J. Guo and W.-B. Chen, Asian J. Chem., 25, 3609 (2013).

5. E. Repo, J.K. Warchol, A. Bhatnagar and M. Sillanpää, J. Colloid Interf. Sci., 358, 261 (2011).

6. G.P. Kumar, P.A. Kumar, S. Chakraborty and M. Ray, Sep. Purif. Technol., 57, 47 (2007).

7. Q. Dong, J.S. Liu, L. Song and G.Q. Shao, J. Hazard. Mater., 186, 1335 (2011).

8. X. Wang, W.X. Zhang, J.S. Liu and L.L. Wu, Asian J. Chem., 25, 6575 (2013).

9. K.Y. Hu, J.S. Liu and K.C. Wang, Asian J. Chem., 26, 2571 (2014).

10. A. Ramesh, H. Hasegawa, T. Maki and K. Ueda, Sep. Purif. Technol., 56, 90 (2007).

11. A.A. Atia, A.M. Donia and A.M. Yousif, Sep. Purif. Technol., 61, 348 (2008).

12. E. Guibal, C. Milot and J.M. Tobin, Ind. Eng. Chem. Res., 37, 1454 (1998).

13. P.K. Chatterjee and A.K. Sengupta, AIChE J., 55, 2997 (2009). 